\title{
Cidade Maravilhosa: o Rio de Janeiro representado pelas letras
}

\author{
Ciudad Maravillosa: Rio de Janeiro, representado a través de la literatura
}

Wonderful City: Rio de Janeiro represented by Literature

Priscilla Oliveira Xavier'

Palavras chave:

Cidade

Representação

Imaginário

Literatura

Moderno
Resumo:

O moderno marca a virada do século XIX para o século XX no Brasil, construindo e se apropriando das cidadescomo espaços privilegiados para a encenação do poder. No período, os imaginários moderno e urbano se difundem na capital da república,inspirando e inflando a cultura.Especificamente pelo ofício das letras, as cidades foram tematizadas à exaustão, sintomatizando o novo período.Nos textos as cidadesdeixam de ser o cenário do que se conta e passam a ser contadas, ganhando feições, afetos e personalidade.E no fenômeno de conferir legibilidade e distinção às cidades, o Rio de Janeiro passou a ser representado como Cidade Maravilhosa. Pretendemos nesse trabalho lançar luzes sobre a associação entre o Rio de Janeiro e o termo Cidade Maravilhosa, buscando a origem do termo e refletindo sobre as formas escritas de representar o Rio de Janeiro. 


\section{Resumen:}

Lo moderno marca el cambio del siglo XIX al siglo XX en Brasil, construyendo y apropiándose de las ciudades como espacios privilegiados para la escenificación del poder. En el periodo, el imaginario moderno y urbano se difunde en la capital de la República, inspirando e inflando la cultura. Específicamente, a través del oficio de las letras, las ciudades han sido tematizadas hasta la extenuación, como un síntoma del nuevo periodo. En los textos, las ciudades ya no son el escenario de lo que es narrado y pasan a ser ellas mismas narradas, adquiriendo carácter, afectos y personalidad. $\mathrm{Y}$ en el fenómeno de conceder legibilidad y distinción a las ciudades, Rio de Janeiro pasa a ser representada como la "Ciudad Maravillosa". Nuestro objetivo, en este trabajo, es destacar la asociación entre Rio de Janeiro y el término "Ciudad Maravillosa", buscando el origen de este término y reflexionando acerca de las formas escritas de representar a la ciudad de Rio de Janeiro.

Palabras clave:

Ciudad

Representación

Imaginario

Literatura

Moderno

\section{Keywords:}

City

Representation

Imaginary

Literature

Modern

\section{Abstract:}

The modern marks the turn of the 19th century to the 20th century in Brazil, building and appropriating cities as privileged spaces for the staging of power. In the period, the modern and urban imaginaries took place in the capital of the Republic, inspiring and inflating the culture. Specifically,through literature, the cities were themed to exhaustion, illustrating the new period. In the texts, citiesare no longer the scenery of what if being narrated and are themselves the narrations, gaining features, affections and character. And in the phenomenon of granting legibility and distinction to the cities, Rio de Janeiro starts being represented as a "The Wonderful City". We aim, on this work, to highlight the association between Rio de Janeiro and the expression"Wonderful City", seeking the origin of the term and reflecting on written forms of representing Rio de Janeiro. 


\section{Cidade Maravilhosa: o Rio de Janeiro representado pelas letras}

\section{O Rio de Janeiro, a capital que inspira}

Produzir uma reflexão sobre as formas escritas que, no início do séc. $X X$, associavam o Rio de Janeiro ao termo "Cidade Maravilhosa" pode à primeira vista parecer uma tarefa simples, mas na prática é um desafio. Ao nos aproximamosda noção de representações de um espaço e tempo, como condensação dos sentidos conferidos ao mundo em um recorte espaço temporal, inevitavelmente nos enveredamos pela história cultural, bem como em suas possibilidades e limitações.

Apenas para citar, entre as possibilidades, temos acesso a fontes e metodologias que nos permitem leituras sobre o referido período. E entre os fatores complicadores, a quantidade de fontes disponíveis é imensa, e a conjuntura que pretendemos complexa, de ebulição de sentidos em torno de um repertório moderno. Nos resta assim impor algum controle na condução da reflexão,propondo um recorte coerente com nosso objetivo e possibilidades e nos abrirmos às contribuições variadas, para além da história, para melhor contemplar as referências de cultura, espaço e temporalidades.

Identificando o Rio de Janeiro, alcançamos uma configuração institucional que por si diz bastante sobre a cidade. Exercendo a capitalidade desde 1763, como sede da colônia, passando pela corte e império, chegando a república na virada do século XIX para o XX, a cidade carrega o repertório simbólico de um longo período em função de destaque. Instrumentalizada espacial, administrativa, política e simbolicamente para expressar um todo,se distingue na estética urbana e engrena o séc. $X X$ com a função de encenar um novo tempo. Temos, portanto, emaranhadas nas formas concretas e simbólicas da cidade as narrativas de poder informadas por fenômenos como o modo de compreender e agir pela razão, a consolidação do sistema republicano e o reordenamento da economia mundial.

$E$ na cidade que encena o novo período, conferimos destaque às atuações dos romancistas, poetas, cronistas e jornalistas do início do século $X X$ e às disputas travadas no campo da cultura. Nos debruçamos sobre o quadro de referências, mesclando realidade e ficção, que expressam as transformações do início do século XX que marcaram o Rio de Janeiro e seus habitantes.

Justificando o peso que conferimos ao papel da cultura no processo de transição, embora seja um exagero afirmar que a cultura indicava como se comportar e fluir no espaço urbano, moderno e civilizado, é inegável a contribuição como mediadora da relação das pessoas com um espaço novo e em transformação.E o foco na forma escrita se assenta na adaptação das narrativas à vida urbana. A capacidade de evocar imagens, simbolizar, ordenar e interpretar, despeito da orientação factual ou ficcional, entram em compasso com as novas formas de atuar no e representar o mundo.

As cidades em geral e o Rio de Janeiro em especial são captados pelas letras e representados na cultura. E nessa conjuntura de conhecer e dar legibilidade à cidade identificamos o surgimento da representação do Rio de Janeiro como "Cidade Maravilhosa". Refletindo sobre o contexto, a forma e a representação descolamos do senso comum o termo Cidade Maravilhosa,naturalizado e estrategicamente trabalhado para a inserção do Rio de Janeiro na competição pela atração de capitais e turismo entre as global cities. 


\section{Em busca da autoria do termo cidade maravilhosa}

Em uma era de marcas e patentes é frequente, e até compreensível, a sanha pela identificação da autoria de determinadas ideias, de modo a assentá-las como um produto. Produto não meramente de um tempo, não singularmente de uma sensibilidade, mas sim adaptável a um mercado. Sem maior necessidade aprofundamento crítico à ordem economia, buscamos a autoria do termo Cidade Maravilhosa. E já iniciamos a busca com algumas sugestões que figuram entre o senso comum e a literatura acadêmica.

Em "O Rio de todos os Brasis: uma reflexão em busca da auto-estima"" Carlos Lessa (2000), logo na introdução, afirma sem vacilar:

O Rio como projeto e sonho foi, na virada do século, a condensação do Progresso, tendo na largura das avenidas, na opulência dos bulevares, no faiscar da iluminação noturna e no circular elegante pela Avenida Central uma comprovação inequívoca. A população, nas calçadas, teria a demonstração concreta da modernidade do brasileiro. A República fez do Rio o espelho da nação como futuro feito presente.

Esta foi uma operação extremamente bem sucedida: o Rio como cartão de visitas do país e certidão de brasilidade, como lugar único que combinava a natureza tropical com a modernidade urbana, foi batizado Ville Merveilleuse pela francesa Jeanne Catulle Mendes, em 1912. Com a marcha de André Filho para o Carnaval de 1935, consagrou-se o epíteto como "hino oficioso" da cidade (LESSA, 2000, p.13)

Segundo o autor, em 1912 a francesa Jane Catulle batizou o Rio de Janeiro ao dar o título de Ville Merveilleuse à sua coletânea de poemas sobre a cidade.
Investigando a referência bastante difundida, alcançamos a informação de que Jeane Catulle visitou o Rio de Janeiro de Setembro a Dezembro de 1911. No período as reformas promovidas por Pereira Passos cintilavam, arrancando suspiros dos estrangeiros e enchendo de orgulho a fina flor da sociedade carioca.

A poetiza francesa desembarcou no Rio de Janeirocom o objetivo de participar de três conferências, uma delas no Teatro Municipal. E como uma figura de bons contatos e prestígio, esteve presente até mesmo em uma audiência com o então presidente da República, Washington Luis P. de Sousa. Com uma estadia de pompa e interlocutores ávidos por suas impressões sobre a cidade reluzindo modernidade, a autora escreve poemas decantando o deslumbramento de sua visita. $\mathrm{Na}$ coletânea de poemas em amor ao Rio de Janeiro, expressou desde sua chegada até os passeios e a partida, exaltando positivamente tudo o que vira e sentira, como é notável em um trecho de"Arrivée dans la baie de Guanabara":

\section{Jamais tant de splendeurs n'ont ébloui les yeux! \\ C'est ici le pays de toute la lumière, C'est ici le pays de la beauté plénière, Des terrestres beautés et des beau- tés des cieux."' (MENDĖS,1913)}

Apesar do enorme prestígio da poetiza e desua gentil obrainspiradapelo encantamento com o Rio de Janeiro, seria precipitado conferir à Jane Catulle a autoria do termo Cidade Maravilhosa. Primeiramente por se tratar de uma impressão estrangeira sobre uma nação "recém criada", uma percepção de fora, sem maiores enraizamentos,envolvimento ou compromisso com a construção do país,quiçá da cidade. Posteriormente porque a época era a de intervenções urbanas adaptando as cidades às conveniências de uma nova configuração econômicamundial e, 
em corolário,ordenamento político. Nada mais provável do que se afetar, estranhar ou se apaixonar, pelo que ao mundo se apresenta como novidade. Para além, o fluxo de pessoas influentes, de políticos a artistas,capazes de dizer e repercutir sobre os lugares, as pessoas e as instituições acabava por chancelareste ou aquele lugar como relevante ou não aos ideais e imaginário moderno.

Alcançamos com tais considerações a ideia de que o dizer sobre as cidades estava na ordem do dia, e que o repertório do que se diz sobre as cidades poderia ser limitado pelos ideais e imaginário moderno. Optamos então por perseguir as possibilidades do termo "Cidade Maravilhosa" já figurar nas escritas que circulavam pela cidade do Rio de Janeiro.

Procedemos um levantamento nos principais periódicos da época. Refinando, selecionamos os dois periódicos de maior circulação, A Notícia e O Paiz, entre anos de 1900 e 1910. E em cada um dos títulos tivemos nove ocorrências, algumas delas em datas anteriores a visita de Jane Cattulle, endossando a hipótese de que a poetiza pode não ter sido exatamente a autora do termo.De início já podemos afirmar que ela estava em compasso com o que era dito sobre cidades em geral e repetitiva com o que era dito sobre o Rio de Janeiro.

Nas primeiras referências no Jornal A notícia temos a Cidade Maravilhosa como um termo aplicável a qualquer cidade. Como no caso encontrado em que a Cidade Maravilhosa é relacionada a da Mil e uma Noites.Uma alusão à cidade criada em uma dimensão fantasiosa, alastrada por um clássico da literatura universal. Trata-se da segunda parte do texto "O aranha Vermelha":

Lufadas de perfume evolaram-se com a fumaça do ópio pelas janelas abertas, onde, como nos quadros esculpidos pelas phantasias, appareciam bellas mulheres perseguidas por grotescos amantes.

Era, para imaginar-se em alguma cidade maravilhosa das Mil e uma noites. (A Notícia, Rio de Janeiro, p. 3, 08 Març. 1901).

Uma segunda ocorrência do termo é encontrada na coluna "Registro". O autor faz entusiasmantes elogios ao progresso e à paisagem urbana, jardins, edifícios e boulevards. Porém, a Cidade Maravilhosa a que se refere é Paris, ao fim identificada como Cidade da Luz:

Paris não muda: e creio, apezar de minha inabalável confiança na certesa do progresso humano, que esta cidade maravilhosa sômente poderia agora mudar...para peor. Agora, para Paris, o progresso só poderia ser a perda de certos feitos: mas como desejar tal progresso, si esses defeitos são justamente um dos maiores encantos e uma das mais raras bellezas da cidade da luz? B. (A Notícia, Rio de Janeiro, p. 2, 13 Jun. 1904)

Na mesma coluna, assinada pelo autor, B., novamente registra-se Cidade Maravilhosa para falar de Paris. O autor descreve fascinado, e com inclinação à distinções sociais, um concurso de janelas floridas que envolve os habitantes da cidade:

Nem tudo é política e indústria, graças a Deus, nesta cidade maravilhosa. Aqui a Poesia creou e mantém o seu domínio inviolável e perpétuo e não deixa que as paixões grosseiras, os appetites damninhose baixos avassalem a vida.

Nos últimos dias de maio, vae ser disputado em Paris um concurso de $<<$ janellas floridas $>>$.

A ideia é uma belleza captivante. 
Não há aqui costureira, modista, griselle modesta, Mimi-Pinson jovial e pobre que não cultive, á janella de sua água furtadalv, algumas flores singelas. (A Notícia, Rio de Janeiro, p. 2, 17Jun. 1904)

O primeiro aparecimento do termo referindo-se ao Rio de Janeiro ocorre em 1907, em um texto intitulado "No Palácio Monroe". A rigor, trata-se de um pequeno equívoco no sistema de busca que acabou sendo incorporado por pesquisadores e curiosos como uma aparição do termo. Em uma leitura atenta percebe-se que maravilhosa é a rapidez da construção e não a cidade.

Está ainda na lembrança de todos os habitantes dessa cidade a maravilhosa rapidez com que o general Dr. Francisco Marcelino de Souza Aguiar concluiu o Palácio Monroe, para qual aproveitou o mesmo plano e grande parte dos elementos que serviram na architetura do $\mathrm{Pa}-$ vilhão brasileiro na Exposição de $S$. Luiz. (A Notícia, Rio de Janeiro, p. 3, 22 Maio 1907)

E a primeira aparição constando o termo cidade maravilhosa relacionada ao Rio de Janeiro em A notícia passa a ser a de uma coluna intitulada "Dez annos atrás", em 1909. Antes de afirmar que em 1909 é a data da primeira aparição do termo no jornal A Notícia é preciso relatar que está indisponível para consulta as edições no ano de 1908. E para complicar um pouco mais a questão, há referências que assinalam o período como o do surgimento do termo, nas crônicas de Coelho Netov. Isoladamente trataremos da crônica do autor, no capítulo seguinte, investigando como mais uma sugestão de autoria do termo "Cidade Maravilhosa"que ganha destaque no senso comum e em referências impressas.
Retomando a ocorrência de 1909, na coluna "Dez annos atrás", o texto aborda a transformação da cidade, se indagando sobre o que era o Rio de Janeiro e o que a cidade passou a ser:

(...) e hoje, dez annos depois, passeando essa cidade de tão belas ruas novas, percorrendo as avenidas, respirando um ar que não é das antigas vielas infectadas, habitando uma nova cidade maravilhosa e salubre, ouvindo o aplauso do estrangeiro (...) (A Notícia, Rio de Janeiro, p.2 , 06 Jun. 1909)

O trecho toma os "dez anos atrás" como marco para a transformação da cidade maravilhosa. Mais do que a estrutura urbana para o gozo de quem habita e transita pela cidade, fica marcado o crédito dado à opinião dos estrangeiros. Devemos ainda destacar o imaginário da cidade modernizada, decantada no embelezamento promovido por Pereira Passos, no saneamento de Oswaldo Cruz e na relevância da impressão dos estrangeiros.

Há uma outra ocorrência da " $\mathrm{Ci}$ dade Maravilhosa" na coluna "Pequenos Echos", em "A notícia” em 1909. Antes mesmo da visita de Jane Catulle, o autor do texto publicado no jornal escreve que a cidade já estava decantada por ilustres estrangeiros.Discorre ainda sobre a maravilha como um culto moderno e sublinha a influência da transformação da cidade para o desenvolvimento do maravilhoso como religião:

O Rio tem já sido de tal modo decantado por estrangeiros ilustres, que deve ser hoje considerado pelos que ainda não o conhecem como uma Cidade Maravilhosa. (...) O progresso moderno é uma sucessão tão vertiginosa de maravilhas umas às outras se eclipsando, que nenhuma, por mais espantosa, já causa impressão. Entretanto o gênio dos homens não esfria em nós 
mais razão por influência do nosso sol e do nosso temperamento não nos podemos furtar ao culto do maravilhoso. Esse maravilhoso é mesmo a mais cultuada religião entre nós, a única talvez que contadíscolos. Sobretudo depois que se transformou a cidade, essa religião desenvolveu-se espantosamente. (A Notícia, Rio de Janeiro, p.1,21 Set. 1909).

E já bem próximo da visita de Jane Catulle, temos mais uma referência da Cidade Maravilhosa em 1910, no texto intitulado "A Cidade":

Dias como o de hontem, pela sua doçura, a luz, a sua alegria são verdadeiras dádivas do céo bordado de leves nuvens, colorido de um meigo azul, um quase dia de primavera, enfim, que pouco falta a chegar, que é mesmo possível que anteceda a sua época própria, para depois se retirar mais cedo o logar ao estio.

E por um dia assim que a cidade meIhor brilha nas suas pompas e galas, ostentando os esplendores de uma cidade maravilhosa, feita de flores e revérberos, deitada numa infinita preguiça, á borda do grande golfo, à sombra de suas florestas onde chalram aves aos milhares. Quem a vir assim, vindo de fora, não se admirará de que a terra seja de poetas e sonhadores; do que mais pasmará é de que com uma natureza assim ella tenha a vida intensa, que fervilha á semana, na lufa-lufa dos seus sem mil negócios. (A Notícia, Rio de Janeiro, p.1, 15Ago. 1910)

O detalhe que grita no texto é a natureza como medida da exaltação para discorrer sobre a cidade. Que aliás, não expressa nada inédito.Explorando as representações dos lugares desconhecidos na América, onde aportavam os navegantes estrangeiros, Sérgio Buarque de
Holanda (2002) trabalhou com a imagem do paraíso, com o objetivo iluminar o motivo edênico no descobrimento e na colonização do Brasil. Refletindo sobre as percepções de tempo, de mundo e de vida no período dos descobrimentos, o autor desvenda um mundo fantástico em par com a realidade que forjava a América Hispânica e lusitana. No trecho de "A Notícia" o motivo edênico é retomado em novas tintas, deslocando o olhar do distante para o próximo.

A potência das narrativas sobre a cidade coladas à exuberância da natureza reverbera em dois sentidos. Em um deles sugere a cidade em uma relação harmoniosa com a natureza. E em outro uma desvalorização do homem local, de suas criações e capacidades. Afinal, o que na cidade é motivo de exaltação diz respeito ao que o homem não criou.

Sobre as representações do lugar que valorizam a natureza temos a reiterada indignação de figuras públicas, mesmo anteriores ao referido trecho de jornal, como fora objetivamente expresso por Machado de Assis (1893), argumentando o quanto a exaltação da natureza subestima a ação do homem:

"O meu sentimento nativista, ou como quer que the chamem - patriotismo é mais vasto, - sempre se doeu desta adoração da natureza. Raro falam de nós mesmos: alguns mal, poucos bem. No que todos estão de acordo, é no pays féerique. Pareceu-me sempre um modo de pisar o homem e suas obras. Quando me louvam a casaca, louvam-me antes a mim que o alfaiate. Ao menos, é o sentimento com que fico; a casaca é minha; se não a fiz, mandei fazê-la. Mas eu não fiz, nem mandei fazer o céu e as montanhas, as matas e os rios. Já os achei prontos, e não nego que sejam admiráveis; mas há outras coisas 
que ver." (crônica de 20 de agosto de 1893 em A Semana)

Continuando a investida nas ocorrências do termo, passamos para o jornal O Paiz, que na capa trazia a informação de ser a folha de maior tiragem e de maior circulação da América do Sul.No periódico a Cidade Maravilhosa também aparece inicialmente distante do Rio de Janeiro, no texto "Paris e a exposição" (O Paiz, Rio de Janeiro, p.2, 9 Fev. 1900). Mas logo em 1904 está registrado em versos irreverentes, que com métrica e rima chafurdam no conteúdo que perscrutamos do imaginário do Rio de Janeiro como cidade moderna,em "Matriculados e não Matriculados". Trata-se de uma troça à repressão municipal nas ruas em meio ao carnaval.

Essa gaiola bonita

Que vai ahi sem embaraços

É a invenção mais catita

Do genial Dr. Pereira Passos

As ruas de ponta a ponta

Subindo e descendo morros,

Por onde passa dá conta

Dos vagabundos cachorros.

Agarra! Cerca! Segura!

- Grita a matilha dos guardas -

Correndo como em loucura

Com um rumor de cem bombardas.

Terra sempre em polvorosa

Bem igual no mundo inteiro,

Cidade maravilhosa!

Salve, Rio de Janeiro!"

(O Paiz, Rio de Janeiro, p.2, 16 Fev. 1904).

No mesmo ano, meses depois, temos uma ocorrência que dá conta da transformação do urbano, em um enorme esforço de melhoramentos para o desenvolvimento das forças econômicas e progresso do Brasil, nas promessas alinhadas na inauguração do governo de Rodrigues Alves, no texto intitulado "Uma obra política":

A população compreendeu bem a grandeza do serviço que o governo vai lhe prestart, negando-se a crear embaraços a sua acção, como queriam agitadores profissionais, antes, facilitando todos os accordos e sujeitando-se a todas as prescrições legaes no bom intent de ver transformada, embellezada e saneada esta cidade maravilhosa, de cuja fama e de cuja força depende o equilíbrio da seiva econômica em todos os orgãos do paiz. (O Paiz, Rio de Janeiro, p.1, 4 Maio, 1904)

Em Dezembro do mesmo ano, verificamos uma nova ocorrência. Saindo do imaginário urbano do progresso, embelezamento e saneamento, a Cidade MaraviIhosa está em uma narrativa de ficção, no texto "O mistério do natal", assinado por Coelho Neto, escritor já referido e cogitado como autor do termo:

Os olhos estendiam-se por uma Cidade Maravilhosa, toda construída em mármore e porphydo, com enormes templos, palácios que eram cidadelas, jardins de redolentes alas, rios beirados de árvores, com as rampas matizadas de flores, Rolando águas serenas, sobre as quaes brilhava a tremelina do luar. (O Paiz, Rio de Janeiro, p.1, 14 Dez. 1904)

Em Abril de 1905 o termo aparece na coluna "O Dia", assinada por Pangloss. Entre outras coisas, Pangloss explica que vindo de São Paulo, estando oito anos ausente, tinha que falar dessa cidade maravilhosa. A cidade maravilhosa é São Paulo. E Pangloss é o nome usado por Alcino Guanabara, que no mesmo ano de 1905 foi nomeado redator chefe de O paiz. Também desvinculado ao Rio de Janeiro o termo aparece em 1907, na coluna "Lucta Romana", rendendo homenagens a Raoul 
Le Boucher. A cidade maravilhosa é Sourgues, na França, onde o lutador nasceu.

O termo volta a aparecer relacionado ao Rio de Janeiro no ano de 1908 , em Agosto e Novembro, para relatar como a cidade estava preparada para receber uma exposição nacional, com a participação dos prósperos Estados da República.

Organizando as ocorrências do termo, incitando mais compreensões do que uma explicação definitiva, temos a "Cidade Maravilhosa"até 1904 aparecendo como referência a cidades reais e fictícias. Em 1904 temos uma primeira referência relacionada ao Rio de Janeiro, em "O paiz", e em 1909 em "A Notícia".Em ambos os casos a referência dialoga com as reformas de Pereira Passos, embebidas no imaginário da cidade moderna.E a despeito das ocorrências relacionadas ao Rio de Janeiro, o termo volta a aparecer para tratar de outras cidades, reais ou fictícias.

Preenchendo a lacuna de 1908, do Jornal "A Notícia", abordaremos a referência de Coelho Neto, mais especificamente o texto apontado como o que dá origem ao termo "Cidade Maravilhosa". Que por seu turno, dá nome tambéma uma coletânea de crônicas do autor.

\section{As crônicas atualizando a cidade}

Buscamos analisar o texto intitulado "Cidade Maravilhosa", de autoria de Coelho Neto, supostamente publicado no jornal "A Notícia", em 1908, indicado em publicações variadas e no senso comum como sendo o autor do título de Cidade Maravilhosa que representa o Rio de Janeiro.

Primeiramente, damos conta do formato do texto. Sintomatizando as tendências do período, ousamos considerar o texto como uma mescla das característi- cas de um conto e de uma crônica. Como conto possui narrador, poucos personagens, um evento ápice, se dividendo em começo, meio e fim. Como crônica é uma narração enxuta e cativante. Identificamos ainda uma justaposição ou aglutinação entre o factual e o ficcional. $O$ conto se desenrola ao sabor da ficção e a crônica como descrição de fatos.

O híbrido nos faz recorrer à compreensão de que a alteração do ritmo da cidade modernizada, a mudança da noção e uso do tempo, provocou rebatimentos em todos os aspectos da vida. Nessa reconfiguração os periódicos foram os responsáveis pelas mudanças nas formas escritas,condicionando a produção ao cotidiano e factual. Em grande medida a crônica se desenvolve como um formato que adaptava a literatura para ser ministrada nos periódicos.E embora pesem críticas ao formato, como uma literatura menor, as crônicas rapidamente caíram no gosto popular, impulsionando a tiragem dos periódicos e incitando os editores a contratar quem fosse capaz de bem produzir no estilo.

Entre a objetividade jornalística e a criatividade literária, as crônicas tematizavam a dinâmica cotidiana e as transformações da vida com entusiasmo, descartando da literatura tradicional os excessos de estilos de linguagem. Por seu conteúdo, tinham como função o entretenimento do público letrado, consumidor de periódicos. Mas como não há entretenimento inocente, de carona com apura distração estava a formação da opinião pública,a incitação do imaginário eo condicionamento a novas sensibilidades relacionadas à vida urbana, para dizer o mínimo.

Retomando a argumentação de que a cidade inspira os escritores e é tematizada nos textos do início do séc. XX, apreendemos a tônica das produções e expressões sensíveis em repertórios da 
modernidade e das idiossincrasias de um país periférico. O que em uma compreensão dura é reconhecer que, a despeito da criatividade artística,as narrativas reverberavam em uma arena de conflitos entre referenciais tradicionais ou modernos, locais ou estrangeiros e entre a interioridade e o racionalismo.

Além dos repertórios de ideais e imaginários, a atividade dos cronistas deu nitidez a um movimento paradoxal. Com efeito, a produção de crônicas na cidade foi dando lugar à cidade crônica.Descrevendo dinâmicas e conferindo caráter à cidade em sintonia com o imaginário urbano e moderno, as crônicas tornaram as cidades conhecidas em suas particularidades e afetos. No tocante à Cidade Maravilhosa, o impulso da imprensa livre e a proliferação de crônicas tematizando o urbano e o moderno fez com que o Rio de Janeiro deixasse de ser o objeto, palco ou cenário do que se conta e passasse a ser o sujeito, sendo contada e ganhando feições e personalidade.

Concluído um preâmbulo, como um texto de forma literária e intenções vacilantes encurralamos "A Cidade Maravilhosa" de Coelho Neto, apontado como origem do termo relacionado ao Rio de Janeiro. Publicado no "artigo 'Os sertanejos', na página 03 , do jornal 'A Notícia', edição de 29.11.1908” (CAMPOS, 1965, p. 76), "A Cidade Maravilhosa", conta a história de Adriana, uma professora da povoação em Barretos. Descreve longamente Barretos, como uma povoação calma, onde se vê poeira e bois passando, só se ouve o coachar dos sapos, e onde nada acontece. Adriana encara o dilema entre se dedicar aos estudos para alçar boa carreira ou ceder às cobranças do pai para arranjar um bom casamento.Levando adiante os estudos, Adriana arranja um contato político que Ihe agiliza uma vaga como professora, em um povoado distante. No povoado em que também nada acontece, dá aulas e mora em um quarto de pensão. E um dia, na pensão, conhece um pintor viajante.

A aparição do pintor é o que dá força para o desenrolar da história. Na caracterização do personagem que irá trazer mudanças na história é possível tomar a profissão de pintor como uma analogia ao sujeito que cria e reproduz imagens de lugares diferentes, como um elemento que flui entre mundos, que comporta, reproduz e cria representações.

Retomando, Adriana e o pintor têm a oportunidade de se aproximar e conversar. O pintor fala ser do Rio de Janeiro e seduz a professora interiorana para lá ir morar com ele, pois na cidade eles poderiam ser felizes. E numa noite de maior entrosamento o pintor a leva pela mão para a beira de uma estrada, alude para um fogaréu longínquo e exclama:

- Linda cidade.

- Onde? perguntou Adriana. E ele apontou o horizonte.

- Ali, pois então? Cidade Maravilhosa! Cidade do sonho, cidade do amor. (NETTO, 1928 ,p.17)

Mas a história não termina na cena de magia e encantamento. O desfecho, de cunho dramático, é o sumiço do pintor, que deixa Adriana abalada. Decidida, na companhia de uma amiga vai até o local apontado pelo pintor.E de perto se depara tão somente com os vestígios da queimada que vira encantada ao longe. Assombrada pela memória da noite de magia e sedução, se põe a chorar, sendo confortada pela amiga que a leva de volta para casa.

Uma possível compreensão da crônica de Coelho Neto está baseada na dualidade entre a real cidade do interior e a cidade do sonho. O pintor é quem seduz Adriana e incita seu imaginário apontando 
para um fogaréu e verbalizando a Cidade Maravilhosa. Em termos precisos, o local apontado era uma alusão à Cidade Maravilhosa e em tempo algum o Rio de Janeiro foi descrito como Cidade Maravilhosa. O fato é que a cidade do Rio de Janeiro passou a ser compreendida como a tal "Cidade Maravilhosa".

A ausência de relação entre a Cidade Maravilhosa e o Rio de Janeiro na crônica de Coelho Neto nos abre um mundo de dúvidas. Com usos anteriores e posteriores, designando o Rio de Janeiro, outras cidade e cidades fictícias, porquê a autoria do termo Cidade Maravilhosa foi conferida a Coelho Neto? Como o termo tornou-se usual? Porquê o termo Cidade Maravilhosa na crônica homônima, não sendo inédito sequer nos textos do autor ${ }^{\mathrm{V}}$, foi associada ao Rio de Janeiro? Tentando iluminar essas e outras questões, abordamos como indiciária a inscrição de Coelho Neto em seu tempo.

As crônicas parnasianas de Henrique Maximiliano Coelho Neto eram caracterizadas pela pompa e formalismo, sem regular artifícios retóricos. Inspirado no consagrado estilo literário francês, o escritor adaptava as paisagens a textos, primando por elementos como a poesia, ritmo, harmonia e beleza. Em "A Cidade Maravilhosa" descreve Barretos como uma povoação triste, de casas espaças, cujos ruídos eram o de sapos, grilos e mugidos, pintando uma paisagem na qual, em suas palavras, os sonhos eram desfeitos. Já a Cidade Maravilhosa era sugerida em oposição a Barretos, a cargo do imaginário.

A obra de Coelho Neto era saboreada e exaltada pelos ávidos e requintados leitores da fina flor da sociedade carioca. Escusado dizer que este apreço não era dos mais abrangentes, e pertinente lembrar que o período era marcado por tensões políticas que reverberavam no plano cultural. Como já assinalado, de um lado ideais inspirados na arte clássica e conservadora, e de outro lado ideais de rupturas artísticas que flertavam com a valorização de uma identidade nacional.

Como capital da República, o Rio de Janeiro era tanto o palco quanto o elemento privilegiado para as disputas políticas e culturais protagonizadas por conservadores e modernistas. E pela junção de elementos e dinâmica do contexto é de se intuir que Coelho Neto tenha se tornado um dos alvos para críticas. Pelos hábitos que cultivava, conteúdo e forma do que produzia e público ao qual se destinava, pesavam-lhe as acusações de que seu trabalho era tão casado com o estilo que se divorciava da literatura como elemento de transformação social, uma vez que todo capricho na forma não incorporava como questão o político, o social ou o moral.

Apesar das críticas ao posicionamento do autor em relação a um movimento cultural, que deu origem a Semana de Arte Moderna, é necessário incorporar mais conteúdos para complexificar a questão. Afinal, Coelho Neto foi um profissional que reagiu, a seu modo e dentro de seus limites, contra a produção literária engessada em crônicas. Por seu gosto, cultuava a forma parnasiana, valorizava a imaginação em detrimento da observação do cotidiano. Produzia textos longos, salpicados de termos raros. Sobre a forma do seu texto, diziam ser enfadonha, acusavam faltar trivialidade em sua inspiração e atacavam o excesso de termos pouco usuais como um exibicionismo intelectual.

A despeito do posicionamento e comprometimento literário, a necessidade de prover recursos parece ter falado mais alto que o idealismo. Coelho Neto passou a escrever crônicas, mas não sem nelas marcar algum teor romântico ou naturalista, conforme mencionados em "A Cidade Maravilhosa". E dando ouvidos às vozes 
em defesa do autor, Fountoura (1944) afirma que "Eu prefiro ver nêle um puro idealista que deveria ter vivido numa época em que o Estado alimentasse os gênios, como Deus alimenta os pássaros para que cantem sem a miséria das contas a pagar." (FONTOURA, 1944, p.124).

\section{Afinal, quem criou a cidade maravilhosa?}

Sem definir uma origem e autoria, nos resta elaborar proposições sobre o emprego do termo relacionado ao Rio de Janeiro, nos questionando sobre sua adesão pela população e sua eficácia simbólica. Optamos por compreensões do termo como uma construção entre o inconsciente coletivo e a representação social.

Lapidando os conceitos, ambos têm uma matriz na psicanalítica, no entanto o inconsciente coletivo tem uma abrangência universal e a representação social se configura mais local e culturalmente, dando suporte para estudos comunicacionais.

O conceito de inconsciente coletivo parte da análise de sonhos e interpretação dos símbolos oníricos. Desenvolvida por Jung (1964), a abordagem tinha como finalidade desvendar a comunicação entre o consciente e o inconsciente. Analisando delírios e alucinações de psicóticos, Jung (1964) percebeu que havia imagens padrões relacionadas a mitos, lendas, contos e demais manifestações que não tinham origem nas percepções, memórias ou experiências conscientes. $\mathrm{E}$ chamou de imagens primordiais as recorrências de modos universais de experiência e de comportamento. Tal psique partilhada é a compreensão do inconsciente coletivo.

As representações sociais, por seu turno, se realizam nas relações mediadas pela linguagem, como fruto da união entre a cultura e a comunicação. A ocorrência se dá em um contexto social, determinação espaço temporal, e ganha impulso amparada por suportes técnicos. Os conteúdos do inconsciente coletivo são apropriados, reelaborados e disseminados por instituições e indivíduos.

Conforme descreve Moscovici (1981) "As representações sociais dizem respeito a "um conjunto de conceitos, afirmações e explicações originados no cotidiano, no desenrolar de combinações interindividuais". Em outros termos, é o dizer sobre algo que adquire importância para uma dada coletividade. E por ser e estar para as interações e a coletivo, às representações sociais não cabem autoria ou propriedade, posto que são essencialmente susceptíveis de transformações na medida do compartilhamento.

\section{Considerações sobre a cidade maravilhosa}

Encaminhado algumas considerações a partir da busca pela origem do termo Cidade Maravilhosa em expressões literárias no período institucional do Rio de Janeiro como capital da república, a partir de dois possíveis autores, Jane Catulle e Coelho Neto, e o levantamento em dois importantes periódicos, entre os anos de 1900 e 1910, frisamos alguns pontos.

Primeiramente, não podemos dedicar à Jeane Catulle a autoria do termo. Antes da visita da poetiza o termo já figurava nos periódicos para se referir ao Rio de Janeiro, a outras cidades modernizadas e até a cidades fictícias. Não seria improvável que o termo figurasse em conversas ilustradas ou frívolas. E sem nenhum demérito à obra da autora, os elementos escolhidos para descrever a cidade na poesia eram próximos aos usados nos textos dos periódicos para falar de uma cidade qualquer ou do Rio de Janeiro.Que por seu turno, eram mais de uma ordem natural, místi- 
ca ou de afetos do que propriamente do urbano construído.

Uma segunda observação se volta justamente para o que é descrito sobre uma cidade e o que é descrito sobre o Rio de Janeiro. Seja a cidade o que for, ela se torna o que dela é narrado. E por conta das narrativas não é preciso ir a Londres para imaginar o Big Ben, o tâmisa e um dia cinza. Não é preciso conhecer Paris para saber da Torre Eiffel. Veneza não é Veneza sem uma feira e um passeio de gôndola. E nesses recortes narrativos, nesses roteiros imagéticos, o Rio de Janeiro estava sendo construído. $\mathrm{E}$ a construção narrativa do Rio de Janeiro induz um retorno ao motivo edênico, fazendo, no entanto, o maravilhamento escoar de um mundo distante e desconhecido para o mundo conhecido e próximo.

Atentamos ainda para o termo "Cidade Maravilhosa" sendo acionado em um contexto de pelejas políticas e pujança cultural, vide a articulação entre a arte pela arte ou a arte engajada ${ }^{\mathrm{VII}}$. Nele a cidade é tanto um palco quanto um objeto. Um palco por ser o espaço privilegiado para encenações, onde a diversidade de narrativas ganha visibilidade e as disputas acontecem. E um objeto na medida em que é incorporada pelas narrativas, sendo pensada, elogiada, criticada, projetada e poetizada.

Pela quantidade e variações das aparições do termo abdicamos da tarefa de especificar uma origem ou autoria. Pois, conforme verificamos, a primeira aparição do termo relacionado ao Rio de Janeiro, nos versos de uma paródia à vigilância do poder público, não fez com que dali em diante ele identificasse exclusivamente o Rio de Janeiro. E mesmo a aparição do termo nas crônicas de Coelho Neto estão mais para uma constituição ficcional de uma cidade do que para a descrição ou elogio à cidade do Rio de Janeiro.
Sobre a inserção do referido escritor, sinalizado como um provável autor do termo Cidade Maravilhosa, insinuamos uma escrita apegada ao período colonial, em uma orientação clássica, entre a parnasiana e o naturalismo. Porém, pressionada pelo teor mais dinâmico e factual, compassada com a república, a objetividade científica e o ritmo da modernidade enxertados nas crônicas.

Factual, crítica, elogiosa, poética ou ficcional, as narrativas confluíram para um só movimento: o de dar legibilidade ao Rio de Janeiro como ambiente urbano. Assim como metáfora de Ítalo Calvino, sobre o cristal e a chama, no limiar do drama urbano, em que "a tensão entre a racionalidade geométrica e emaranhado de existências humanas" (CALVINO, 1997, p.85), temos narrativas sensíveis da cidade versus a ciência do urbano.

\section{Bibliografia}

ASSIS, Machado de. Obras completas. A Semana (1892-1893). Rio de Janeiro; São Paulo; Porto Alegre: W.M. Jackson Inc., 10 vol.

CALVINO, Ítalo. Seis propostas para o próximo milênio. São Paulo: Companhia das Letras, 1997.

CAMPOS, A. da Costa S. Dicionário de curiosidades do Rio de Janeiro. São Paulo: Comércio e Importação de Livros; 1965.

COELHO NETO. Cidade Maravilhosa. São Paulo: Companhia Melhoramentos. 1928.

HOLANDA, Sérgio Buarque de. Visão do Paraíso: os motivos edênicos no descobrimento e colonização do Brasil. São Paulo: Editora Brasiliense, $6^{a}$ edição, $2^{\mathrm{a}}$ reimpressão, 2002.

JUNG, C.G. O Homem e Seus Símbolos. Rio De Janeiro: Aldus, 1964. 
LAPLATINE, François; TRINDADE, Liana S. O que é imaginário. São Paulo, Ed. Brasiliense, 2003. Coleção Primeiros Passos, nº 309.

LESSA, Carlos. O Rio de todos os Brasis. Uma reflexão em busca de auto-estima. Rio de Janeiro, Ed. Record, 2000.

LOPES, Antonio Herculano; VELLOSO, Monica Pimenta; PESAVENTO, Sandra Jatahy (org.). História e linguagens: texto, imagem, oralidade e representações. Rio de Janeiro: 7Letras, 2006.

MARGATO, Izabel; GOMES, Renato Cordeiro. (org.). Literatura/ Política / Cultura: (1994-2004). Belo Horizonte: Editora UFMG, 2005.

MENDĖS, J. C. La Ville Merveilleuse. Paris: E. Sansot \& Cie;1913.

MOSCOVICI, S. A Representação Social da Psicanálise. Rio de Janeiro: Zahar, 1981.

RESENDE, Beatriz (org) Cronistas do Rio. Rio de Janeiro: José Olympio Editora. 2001. 2a edição.

SANTUCCI, Jane. Babélica Urbe. O Rio nas crônicas dos anos 20. Rio de Janeiro: Ed. Rio Books, 2015. cando elementos da natureza: "Nunca tanto esplendor deslumbrou os olhos! / Esta é a terra de toda a luz, / Esta é a terra da beleza plenária / Belezas terrestres e belezas do céu.

IV Uma parte do telhado que no período era frequentemente destinada aos criados.

V Coelho Neto publicou o "artigo 'Os sertanejos', na página 03, do jornal 'A Notícia', edição de 29.11.1908" (CAMPOS, 1965, p. 76). A informação circula e chegou a ser usada na página pessoal do prefeito Eduardo Paes até 2014. No entendo, a página e seu conteúdo foram retirados do ar. Embora seja possível ver um link com a informação em um profile em homenagem a Coelho Neto no Facebook em https://www.facebook.com/familiacoelhonetto/. Acesso em: 17 Set. 2016, na postagem cujo título é "Há 105 anos, Rio era chamado de Cidade Maravilhosa pela $1^{\mathrm{a}}$ vez / Eduardo Paes, prefeito do Rio".

VI Conforme já abordamos, no texto de ficção "Mistério do Natal" (O Paiz, Rio de Janeiro, p.1, 14 Dez. 1904), Coelho Neto usara o termo Cidade Maravilhosa.

VII A arte e a cultura foram campos férteis para equalizar críticas e propostas para ressignificar e impulsionar um país que engrenava na república e ensaiava um urbano moderno em um espaço exemplar limitado, insuficiente para redimir as muitas faltas do país. A potência da arte e da cultura na capital se alastrou, ligando artistas de diferentes estados em um movimento de ruptura com os conceitos clássicos europeizados e adesão a ideias, elementos, técnicas e sensibilidades em referência ao nacional. E o projeto de uma cultura autenticamente brasileira culminou na Semana de Arte Moderna, em 1922.

\author{
Recebido em 22/02/2017 \\ Aprovado em 15/03/2017
}

I Priscilla Oliveira Xavier. Doutoranda do Instituto de Pesquisa e Planejamento Urbano e Regional da Universidade Federal do Rio de Janeiro, Brasil. Contato: priscillaxavier@gmail.com

II A obra faz parte da Coleção Metrópoles, da Editora Record. O autor, convidado a falar sobre sua cidade, examina o Rio de Janeiro como lugar, memória, representação, sonho e projeto global no imaginário nacional e local.

III Em uma tradução nada rigorosa, sobretudo por conta do teor poético e expressões da época, é notável os rasgados elogios em êxtase com a cidade, desta- 